\title{
Assessing river stability and hydraulic geometry of fluvial river in Malaysia
}

\begin{abstract}
The fluvial geomorphological descriptions of rivers are very important to maintain the natural presence through studying the river stability and sediment transport research. Lack of knowledge on fluvial characteristics will lead to improper water resources management in long term. This research was focused to determine the fluvial river characteristics, to identify the management interpretation of the river stability and to assess the variation of flow regime and equilibrium geometry. The assessment of Rasau River was taken at different morphological appearance such as bedrock, cascade, pool, plain and step-pool. At station data collection were river width, velocity, bed materials, slope of the channel, bank slope and longitudinal profile. Classification of Rasau River were found that RCS1, RCS2, RCS3, RCS4, RCS5, RCS6, RCS7, RCS8 are classified as B4, B3, G4, F3b, $\mathrm{F} 2 \mathrm{~b}, \mathrm{E} 5 \mathrm{~b}, \mathrm{~B} 5$ and B5 respectively. Based on the river classification, the conditions of cross sectionsRCS4and RCS5 are not stable with sediment load low to very high and the energy of water to the stream also shows low to moderate. Low energy of water flow can lower sediment transport rates thus in long term will cause aggradation and channel narrowing. At RCS1,2, 3, 6, 7 and 8 are classified as a stable cross section with bank vegetation as a component of the cross-section stability. The energy of water is in a range of high to moderate and the sediment load is in a range of low to moderate. On the assessment of the equilibrium geometry, Width, $\mathrm{B}=\mathrm{aQb}$, Depth, $\mathrm{D}=\mathrm{cQf}$, and Velocity, $\mathrm{v}=\mathrm{kQm}$. This study was found that hydraulic geometry equations for Rasau River are $\mathrm{B}=$ 12.3Q0.2, $\mathrm{D}=0.9 \mathrm{Q} 0.5, \mathrm{~V}=0.09 \mathrm{Q} 0.3$. It was successfully verified that the hydraulic geometry parameters satisfy continuity equation where the summation of the exponents and the multiplication of the coefficients must give a mathematical value of unity thus specify that $\mathrm{Q}=\mathrm{BDV}$. The coefficient of width (a value) shows the highest, this shows that the widening of the river can increase the significant change of the flow rate of the river.
\end{abstract}

Keyword: Fluvial geomorphology; River stability; Classification of river; Hydraulicgeometry 